O. Paut MD, ${ }^{*}$ L. Mély,* L. Viard MD,* M.A. Silicani MD,* J.M. Guys MD, $\dagger$ J..Camboulives MD*

\title{
Acute presentation of congenital diaphrag- matic hernia past the neonatal period: a life threatening emergency
}

Purpose: Major gastric distension in the lefi hemithorax can threaten life in patients with congenital diaphragmatic hernia $(\mathrm{CDH})$ presenting after the neonutal period. After presentation of two paediatric cases, guidelines for the optimal care of these patients are given.

Clinical features: Both children had respiratory and cardiocirculatory compromise on arrival. The diagnosis of late presenting $\mathrm{CDH}$ was made and the severity of symptoms was related to a voluminous distension of an intrathoracic stomach. Successful placement of an naso-gastric tube in the first patient, lead to a rapid clinical improvement, allowing surgical repair. In the second patient, oro- or naso-gastric decompression was not possible and, while the lungs were mechanically ventilated and the patient was prepared for surgery, a sudden cardiocirculatory arrest was managed by external chest compressions and rescuscitation drugs. Transthoracic percutaneous decompression of the stomach was the sole treatment allowing spontaneous cardiac activity to reappear, and haemodynamic condition to normalize. However, the child died from brain death after this episode.

Conclusion: Gastric decompression is the key for the treatment of patients with $\mathrm{CDH}$ who present respiratory and/or cardiocirculatory distress due to the intrathoracic distension of the stomach. If an oro- or naso-gastric decompression is not possible, then radiologically directed percutaneous

\section{Key words}

ANAESTHESIA: paediatric;

COMPLICATIONS: diaphragmatic hernia, congenital; VENTILATION: diaphragm, failure.

From the Départements d'anesthésie-réanimation pédiatrique $(*)$ et de chirurgie pédiatrique ( $\dagger$ ). Groupe hospitalier de la Timone, Bd Jean Moulin, 13385 Marseille cedex 5, France. Address correspondence 1o: Dr. Olivier Paut, Département d'anesthésie-réanimation pédiatrique, Groupe hospitalier de la Timone, Bd Jean Moulin, 13385 Marseille cedex 5, France.

Accepted for publication 31st January, 1996. decompression under local ancesthesia is required. After decompression, the patient is prepared for surgery, with particular emphasis on fluids infusion, in order to correct the frequently associated hypovolaemia.

Buts: La dilatation aiguë de l'estomac dans l'hemithorax gauche est une urgence vitale chez les patients qui présentent une hernie diaphragmatique congénitale $(H D C)$ à révélation tardive. Après la description de deux cas pédiatriques, des recommandations pour la prise en charge optimale de ces patients sont discutées.

Présentation clinique: Les deux enfants présentaient à la fois une détresse respiratoire et cardiocirculatoire à leur arrivée. Le diagnostic de HDC était porté et la gravité du tableau mis sur le compte d'une dilatation gastrique importante, dans l'hémithorax gauche. La mise en place d'une sonde nasogastrique chez le premier patient a entraîné une amélioration clinique rapide, permettant la réparation chirurgicale. Pour le deuxième patient, la décompression de l'estomac par sonde oro ou naso-gastrique n'a pas été possible, et, alors que le patient était en ventilation contrôlée sous respirateur et préparé à l'intervention, un arrêt cardiocirculatoire brutal est survenu, immédiatement pris en charge par la réalisation d'un massage cardiaque externe et injection de drogues d'urgence. La décompression transcutanée de l'estomac a été la seule thérapeutique permettant la reprise d'une activité cardiaque spontanée et la normalisation progressive de l'état hémody. namique. Malheureusement, l'enfant devait décéder de mort cérébrale à la suite de cet épisode.

Conclusion: La décompression gastrique est l'élément-clé du traitement des patients ayant une HDC à révélation tardive se présentant avec une détresse respiratoire et cardiocirculatoire liée à la dilatation gastrique intrathoracique. Si la décompression par l'intermédiaire d'une sonde gastrique n'est pas possi. ble, il faut alors envisager la réalisation d'une décompression par ponction percutanée de l'estomac, avec l'aide d'une radioscopie, sous anesthésie locale. Après la décompression, le patient est préparé à l'intervention, avec une attention particulière sur l'expansion volémique qui vise à corriger une hypovolémie, très fréquente dans ce contexte. 
Most congenital diaphragmatic hernias (CDH) occur in the neonatal period and represent a life threatening disorder with an overall mortality of $40-60 \%$. The current treatment aims to obtain preoperative stabilization with the use, if necessary, of invasive procedures such as extracorporeal membrane oxygenation. This management has improved the outcome, but the mortality of $\mathrm{CDH}$ remains high. ${ }^{1.2}$ Less frequently, $\mathrm{CDH}$ can be diagnosed later in life, some series relate up to $10 \%$ of congenital $\mathrm{CDH}$ having initial symptoms after the neonatal period. ${ }^{3-10}$ Late presenting $\mathrm{CDH}$ has a better prognosis due to the absence of pulmonary hypoplasia and pulmonary hypertension that augment the severity of neonatal $\mathrm{CDH}$, but its morbidity and mortality are still considerable. ${ }^{3-10}$ In this paper we present the cases of two children with late $\mathrm{CDH}$, presenting with respiratory and circulatory distress due to massive intrathoracic gastric distension, and we make some propositions to achieve the optimal care of these children.

\section{Case reports}

\section{Case I}

A five-year-old boy, weighing $18 \mathrm{~kg}$, had a past medical history of abdominal pain. Two months before admission, he was hospitalized for a suspicion of bowel intrasusseption; radiological investigations (chest $x$-ray and abdominal echography) were considered to be normal and he was discharged. His history consisted of abdominal symptoms (vomiting, diarrhoea) associated with respiratory distress : tachypnoea (respiratory rate $=52$ bpm), cyanosis breathing room air which was treated with $3 \mathrm{~L} \cdot \mathrm{min}^{-1}$ of nasal oxygen. Arterial blood gas analysis showed a metabolic acidosis : $\mathrm{pH}=7.18 ; \mathrm{PCO}_{2}$ $=31 \mathrm{mmHg} ; \mathrm{PO}_{2}=110 \mathrm{mmHg} ; \mathrm{BE}=-15$. Cardiocirculatory examination revealed signs of shock: tachycardia $\left(H R=170\right.$ beats $\left.\cdot \mathrm{min}^{-1}\right)$, skin mottling and cool extremities, and blood pressure $90 / 50 \mathrm{mmHg}$. Also, he was thirsty. During chest auscultation, borborygmi were heard over the left hemithorax and the heart sounds were deviated to the right. Chest $x$-ray showed the bowel to be in the left hemithorax with gastric distension and mediastinal shift to the right. After the difficult placement of a gastric tube, suction of the stomach contents produced rapid improvement in the clinical condition. Preoperative thoraco-abdominal echography, showed the intrathoracic position of the stomach, spleen and a portion of bowel. A rapid fluid expansion was performed with Ringer's lactate $(100 \mathrm{ml})$ and hydroxy ethyl starch $(400 \mathrm{ml})$. Anaesthesia then was induced with atropine $(250 \mu \mathrm{g})$, thiopentone $(60 \mathrm{mg})$, pancuronium $(1.5 \mathrm{mg})$ and fentanyl $(25 \mu \mathrm{g})$, and maintained with isoflurane $(0.5-1 \%)$, fentanyl $\left(4 \mu \mathrm{g} \cdot \mathrm{kg}^{-1} \cdot \mathrm{hr}^{-1}\right)$ and pan- curonium ( $0.4 \mathrm{mg}$ bolus). The patient was ventilated and the mechanical ventilation parameters were as follows: $\mathrm{RR}=25 \mathrm{bpm}, \mathrm{Vt}=180 \mathrm{ml}, \mathrm{FIO}_{2}=0.5$. Nitrous oxide was avoided, and the patient was breathing oxygen in air. Fluid expansion was continued with $400 \mathrm{ml}$ of Ringer's lactate (i.e., $11 \mathrm{ml} \cdot \mathrm{kg}^{-1} \cdot \mathrm{hr}^{-1}$ ), and peroperative haemodynamic conditions were satisfactory. Surgery was performed after a left subcostal incision showing the posterolateral defect and confirmed herniation in the left hemithorax of the stomach, the spleen and a part of the left colon. The postoperative course was uneventful and he was weaned from the ventilator after $12 \mathrm{hr}$. Postoperative $x$-rays showed a left hemithorax opacity, due to an insufficient pulmonary reexpansion, that was corrected in the first few postoperative days.

\section{Case 2}

A 14-mo girl, weighing $10 \mathrm{~kg}$, with a past medical history of gastro-oesophageal reflux, was referred to our paediatric intensive care unit for management of her respiratory distress. The day before, she had presented with fever, vomiting and respiratory discomfort. Chest $x$-ray revealed a large radiolucency in the left hemithorax, with mediastinal deviation to the right, and she was hospitalized. The diagnosis of $\mathrm{CDH}$ was made and, as respiratory signs worsened, she was transferred to our hospital. On arrival, she presented with tachypnoea (respiratory rate $=50 \mathrm{bpm}$ ) and nasal flaring; breath sounds were dimished over the left hemithorax, and heart sounds were deviated to the right. Oxygen saturation $\left(\mathrm{SpO}_{2}\right)$ was $100 \%$ with oxygen administred via a face mask. Arterial blood gas analysis showed a moderate metabolic acidosis: $\mathrm{pH}=7.33 ; \mathrm{PCO}_{2}=32 \mathrm{mmHg} ; \mathrm{PO}_{2}$ $=115 \mathrm{mmHg}$, base excess $=-8$. There were cardiovascular signs of shock: tachycardia $\left(180 \mathrm{~b} \cdot \mathrm{min}^{-1}\right)$, hepatomegaly, delayed capillary refilling, while systolic blood pressure (SBP) was $120 \mathrm{mmHg}$. Chest $x$-ray showed a mediastinal shift to the right, due to the presence of a large opacity and air abnormality, lying in the left hemithorax (Figure).

Placement of a naso- or orogastric tube was impossible. The girl was then prepared for surgery. Induction of anaesthesia was performed with atropine $(150 \mu \mathrm{g})$, succinylcholine $(20 \mathrm{mg})$, fentanyl $(50 \mu \mathrm{g})$ and midazolam ( $2 \mathrm{mg}$ ), the trachea was intubated with a $4.0 \mathrm{~mm}$ uncuffed tube, and the lungs were mechanically ventilated with $100 \%$ oxygen. Induction of anaesthesia was followed by a cardiovascular collapse (HR $=140$ beats $\cdot \min ^{-1}, \mathrm{SBP}=50 \mathrm{mmHg}$ ) that responded well to fluid expansion, $150 \mathrm{ml}$ hydroxyethylstarch, and infusion of dobutamine, $15 \mu \mathrm{g} \cdot \mathrm{kg} \cdot \mathrm{min}^{-1}$, with an increase of SBP to $80 \mathrm{mmHg}$. Invasive monitoring, including the insertion of a central venous line via the external jugular 


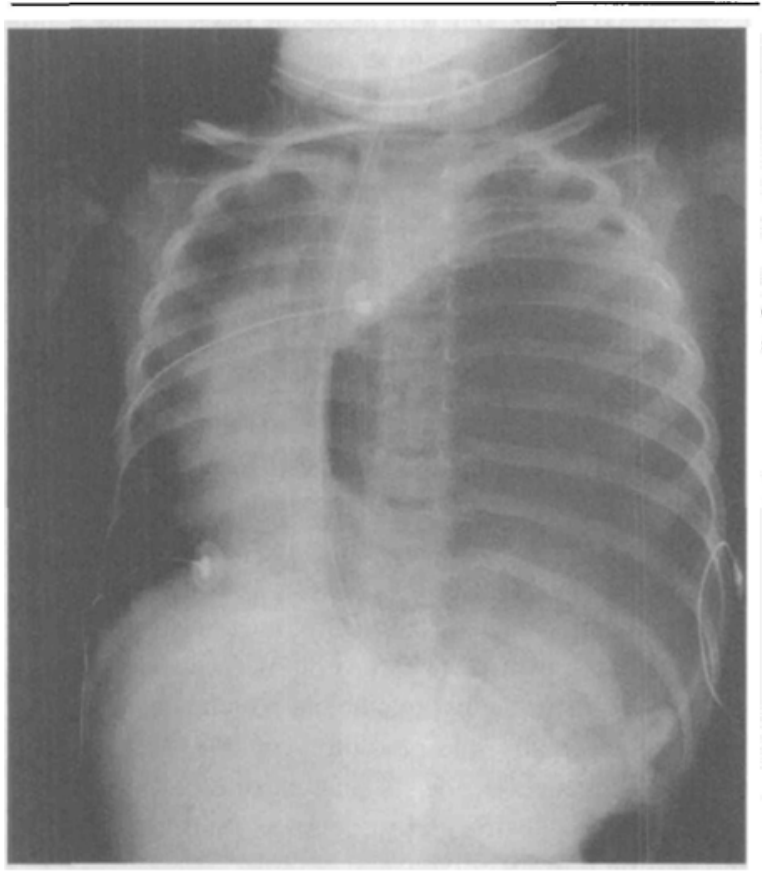

FIGURE Chest $x$-ray of 14-mo-old girl showing large gastric distension in the left hemithorax with marked mediastinal deviation. Note the gastric tube, with the tip lying in the lower oesophagus making gastric suction impossible.

vein, a femoral arterial catheter and a bladder catheter were put in place. She was paralysed and sedated with intermittent bolus doses of vecuronium $(1.2 \mathrm{mg})$ and fentanyl $(25 \mu \mathrm{g})$. Shortly before transport to the OR, she coughed during mechanical ventilation, and vecuronium $(1.2 \mathrm{mg})$ was administered, that was followed by cardiac arrest. Chest compressions were initiated immediately and produced blood pressure wave on the monitor. Despite the administration of epinephrine (bolus doses of $100 \mu \mathrm{g}$, total dose of $1 \mathrm{mg}$ ), sodium bicarbonate (30 mmol), calcium chloride (100 mg), spontaneous cardiac activity did not reappear. A right pneumothorax was dismissed after ineffective needle aspiration. As there was no clinical improvement after 10-15 min of the resuscitation manoeuvers, transthoracic drainage of the stomach was performed, using a $6 \mathrm{~F}$ silicone catheter (pleurocath@, Plastimed, Saint Leu la forêt, France). A large amount of air under tension and gastric fluid were suctioned. The decompression was followed immediately by rapid improvement of the cardiovascular condition and spontaneous cardiac activity reappeared. Epinephrine infusion was started, at the initial dose of 0.4 $\mu \mathrm{g} \cdot \mathrm{kg}^{-1} \cdot \mathrm{min}^{-1}$. At this time BP was $75 / 47 / 36 \mathrm{mmHg}$, $\mathrm{HR}=188$ beats $\cdot \mathrm{min}^{-1}$ and arterial blood gas analysis showed a marked mixed acidosis: $\mathrm{pH}=7.03 ; \mathrm{PCO}_{2}=73$ $\mathrm{mmHg} ; \mathrm{PO}_{2}=150 \mathrm{mmHg}$; base excess $=-11$, central venous pressure $=-4 \mathrm{mmHg}$. Hepato-megaly was no longer present and further fluid expansion with $150 \mathrm{ml}$ hydroxyethylstarch and $100 \cdot \mathrm{ml}$ Ringer's lactate was used, to correct the hypovolaemia. Cardiovascular status remained stable; bilateral lung crepitations and foamy expectorations were present, but mechanical ventilation with oxygen was easy. Further blood gas analysis showed a metabolic acidosis: $\mathrm{pH}=7.18, \mathrm{PCO}_{2}=33$ $\mathrm{mmHg}, \mathrm{PO}_{2}=322 \mathrm{mmHg}, \mathrm{BE}=-14$, that was progressively corrected. After decompression, a nasogastric tube was ..inserted without difficulty. Control $x$-ray showed mild mediastinal deviation, a normal right lung and a left thoracic opacity, suggesting the presence of pleural effusion and atelectasis. The gastric tube terminated in the left hemithorax. At the end of this resuscitation, the pupils showed bilateral enlargment and further investigations confirmed brain death. No post mortem examination was performed.

\section{Discussion}

The two children presented had both respiratory and circulatory distress on admission, secondary to the presence of CDH. In these cases, large gastric distension caused compression of the left lung, and some right lung compression. This atelectasis produced inadequate ventilation and hypoxia. The prominent cardiovascular involvement in the two patients who showed signs of shock during their initial management, was probably due to several factors. Firstly, the two children had gastrointestinal obstruction and were hypovolaemic. Secondly, mediastinal shift can produce haemodynamic alterations by reducing venous return. If it is pronounced, it can result in an almost total obstruction of the inferior vena cava-right atrial junction, thus reducing even more this return further and leading to a cardio-circulatory arrest. The second patient probably had a cardiac arrest of this type. Induction of anaesthesia was followed by cardiovascular collapse, corrected with fluid expansion. Whilst receiving mechanical ventilation, respiratory and cardiocirculatory systems were critical but stable. However, just before transportation to the OR coughing led immediately to cardiac arrest. We hypothetize that coughing may have caused further herniation of viscera in the left hemithorax (due to an increase of intraabdominal pressure during coughing), leading to a dramatic decrease in venous return. The cause of brain death is more complex. Although cardiac arrest lasted 10-15 min, it was managed immediately by chest compression and infusion of resuscitation drugs. Concomittant invasive monitoring of blood pressure confirmed the apparent effectiveness of these manoeuvers, so that aggravating factors must have been associated. We suggest that brain death was the result of ischaemic and 
anoxic brain damage secondary to hypoxaemia and to a decrease in the cerebral perfusion pressure. The latter was probably due to a combination of a decrease of cerebral arterial perfusion and a decrease of cerebral venous drainage.

Severe complications have been described in patients having a late presenting $\mathrm{CDH}$. The occurrence of an acute pulmonary oedema shortly after the surgical correction of the herniated viscera in the abdominal cavity which is a re-expansion pulmonary oedema, can involve the ipsi and/or contralateral lung. ${ }^{11}$ The treatment of reexpansion pulmonary oedema is symptomatic, oxygen and mechanical ventilation with PEEP. Necrosis and ischaemic lesions of the herniated viscera have been also described. ${ }^{12}$ Sudden cardiorespiratory arrest is the main complication of late presenting $\mathrm{CDH}$ and has been described occasionally. In Berman's series of 26 cases of late $\mathrm{CDH}$ over $20 \mathrm{yr}$, two deaths occured as a result of cardiorespiratory arrest in previously healthy children. The suggested aetiology was mediastinal compression by the herniated viscera, but no details are avaliable in the article. ${ }^{3}$ In 1971, Fromm and Lucas described an unusual complication of $\mathrm{CDH}$ in a 37 -yr-old man. He was hospitalized for abdominal wounds secondary to a gunshot. Preoperative investigations revealed a large left diaphragmatic hernia with mediastinal shift to the right. During emergency surgery, a posterolateral diaphragmatic defect was confirmed, but attempts to reduce the herniated intestines from the thorax were unsuccessful, due to multiple, firm adhesions. The postoperative course was marked by respiratory difficulties. On day 1 , the mediastinal shift was increased, and he presented with tachypnoea. On day 2, respiratory distress was more obvious, and marked mediastinal deviation was present. Mechanical ventilation was started but, shortly after, a fatal cardiac arrest occured unexpectally. At autopsy, bilateral atelectasis, severe mediastinal shift and large gastric distension in the left hemithorax were found. The authors suggested that the cause of the death was the increase of the mediastinal shift leading to a decrease of venous return, associated with the increase of pulmonary compression leading to inadequate ventilation and hypoxia. ${ }^{13}$

In view of our experience with these two patients and the literature, we propose some guidelines for the optimal care of such cases. The first stage of the treatment, of critical importance, is to decompress the thoracic contents. Insertion of an oro- or naso-gastric tube is difficult, due to anatomical disturbance of the gastrooesophageal junction, but it is possible. In patient \#1, most of the clinical features of respiratory and circulatory distress disappeared after suction of the gastric contents. Sometimes, oro- or naso-gastric tube insertion is impossible, even in experienced hands. In such cases, one must consider thoracic decompression with a radiographically directed percutaneous puncture of the distended stomach. Our second patient could have benefited from transthoracic gastric puncture earlier in her clinical course. One other relevant point of the management of these patients is the choice of anaesthesia technique. Percutaneous drainage of the stomach can be performed with minimal, titrated sedation with additional local anaesthesia completed by the surgeon, or with local anaesthesia alone. If general anaesthesia is prefered, the use of spontaneous ventilation (during inhalational anaesthesia for example) will probably be the most convenient method. Positive pressure ventilation will increase the intrathoracic pressure and cannot be recommended. After gastric decompression the second stage of the treatment consists of preparing the patient for the surgery. Volume expansion is necessary, to correct the hypovolaemia which is usual in our experience. Finally, the possibility of re-expansion pulmonary oedema after the surgical closure of the posterolateral defect justifies close clinical and radiological monitoring postoperatively.

In conclusion, gastric distension is a severe and life threatening complication in patients with a $\mathrm{CDH}$ diagnosed past the neonatal period. The optimal care of such patients relies on prompt diagnosis of $\mathrm{CDH}$ and recognition of the severity of the patient's condition who present respiratory and/or cardiocirculatory compromise owing to the intrathoracic gastric distension. The first step in management is to provide efficient gastric emptying. Gastric suctioning can be performed with the use of a naso- or oro-gastric tube, but its insertion is difficult and may be impossible. In the latter case, transthoracic puncture of the distended stomach, using a needle, allows rapid decompression of gastric contents, and leads to a prompt improvement in the patient's clinical condition. Surgery can be then performed, after correction of the frequently associated hypovolaemia.

\section{References}

1 Nakayama DK, Motoyama EK, Tagge EM. Effects of preoperative stabilization on respiratory system compliance and outcome in newborn infants with congenital diaphragmatic hernia. J Pediatr 1991; 118: 793-9.

2 Rice $\mathrm{W}$, Baker SB. Congenital diaphragmatic hernia. Does extracorporeal membrane oxygenation (ECMO) improve survival ? Paediatric Anaesthesia 1993; 3: 205-8.

3 Berman L, Stringer $D$, Ein SH, Shandling $B$. The latepresenting pediatric Bochdalck hernia: a 20-year review. J Pediatr Surg 1988; 23: 735-9.

4 Wiseman NE, MacPherson RI. "Acquired" congenital diaphragmatic hernia. J Pediatr Surg 1977; 12: 657-65.

5 Newman BM, Afshani E, Karp MP, Jewett TC Jr, Cooney 
$D R$. Presentation of congenital diaphragmatic hernia past the neonatal period. Arch Surg 1986; 121: 813-6.

6 Heaton ND, Adam G, Howard ER. The late presentation of postero-lateral congenital diaphragmatic hernias.

Postgrad Med J 1992; 68: 445-8.

7 Nitecki S, Bar-Maor JA. Late presentation of Bochdalek hernia: our experience and review of the literature. Isr J Med Sci 1992; $28: 711-4$.

8 Hight DW, Hixson SD, Reed JO, Watts FB Jr, Hertzler JH. Intermittent diaphragmatic hemia of Bochdalek: report of a case and literature review. Pediatrics 1982; 69: 601-4.

9 Weber TR, Tracy $T J r$, Bailey PV, Lewis JE, Westfall S. Congenital diaphragmatic hernia beyond infancy. Am J Surg 1991; 162: 643-6.

10 Osebold WR. Soper RT. Congenital posterolateral diaphragmatic hernia past infancy. Am J Surg 1976; 131: 748-54.

11 Paut O, Gaillat F, Delarue A, Bonneru JJ, Chauvet V, Camboulives $J$. Acute pulmonary oedema following repair of congenital diaphragmatic hernia. Paediatric Anacsthesia 1992; 2: 339-42.

12 Schmitt F, Becmeur F, Fischbach M, Geisert J, Sauvage P. Les hernies diaphragmatiques à révélation tardive chez l'enfant. A propos de 13 observations. Ann Pédiatr 1995; 42: 176-84.

13 Fromm SH, Lucas CE. An unusual complication of chronic diaphragmatic hernia in an adult patient. J Thorac Cardiovasc Surg 1971; 61: 654-6. 